\title{
Adsorption heat pumps for heating applications: a review of current state, literature gaps and development challenges
}

\author{
João Miguel Serras Dias a,b,*, Vítor António Ferreira da Costa a,b \\ a Department of Mechanical Engineering, University of Aveiro, Campus Universitário de \\ Santiago, 3810-193 Aveiro, Portugal \\ b TEMA - Centre for Mechanical Technology and Automation, University of Aveiro, Campus \\ Universitário de Santiago, 3810-193 Aveiro, Portugal \\ * Corresponding author tel.: +351 234370830; fax: +351 234370830; \\ web: http://www.ua.pt. \\ E-mail addresses: joaomdias@ua.pt (J. M. S. Dias); v.costa@ua.pt (V. A. F. Costa)
}

\begin{abstract}
A review of the most relevant work on the field of adsorption heat pumps with emphasis on heating applications is presented, covering the working principle, physical models, adsorption equilibrium and kinetics, adsorbent material physical and thermodynamic properties, adsorbent bed designing and operating conditions. The major literature gaps and development challenges of adsorption heat pumps for heating applications are identified and discussed. A bridge between materials and system level studies is lacking. The simultaneous investigation of the adsorption kinetics, adsorbent bed specifications, operating conditions and interaction between all the system components is missing in the literature. Detailed information required for the development and validation of physical models is often not provided in the experimental studies. A physical model that considers an entire adsorption heat pump system, which is required for performance predictions and system's optimization, cannot be found in the literature. To improve the adsorption heat pump system's performance the heat and mass transfer resistances need to be minimized by developing new adsorbent materials and better interaction between the adsorbent bed and the wall of the duct where the heat transfer fluid flows. In
\end{abstract}


addition, operation modes optimized for the desired application can also contribute to improving the system's performance.

\section{Keywords}

Adsorption heat pump; Heating applications; Renewable energy; Adsorption heating; System's performance; Physical model 


\section{Contents}

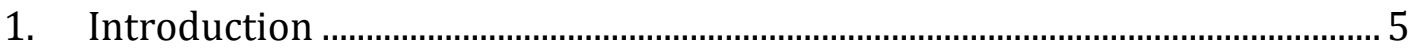

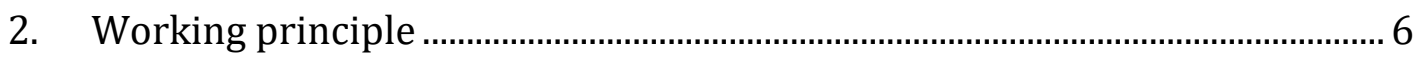

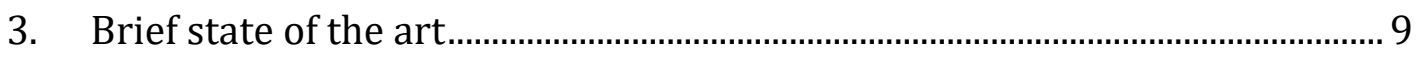

3.1. Physical models and numerical methods .............................................. 9

3.2. Adsorption equilibrium ......................................................................10

3.3. Adsorbent-adsorbate working pairs …................................................11

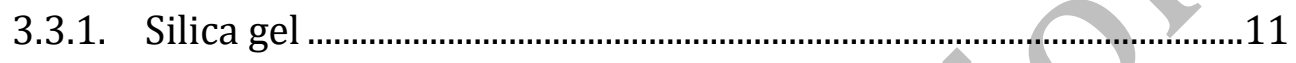

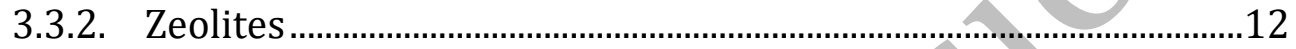

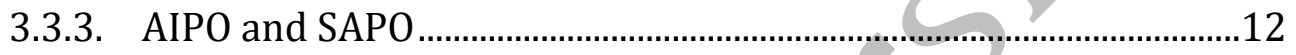

3.3.4. Activated carbons ..............................................................................12

3.3.5. Composite adsorbents.......................................................................12

3.3.6. Metal-Organic frameworks (MOFs) ................................................13

3.4. Adsorbent physical and thermodynamic properties ............................13

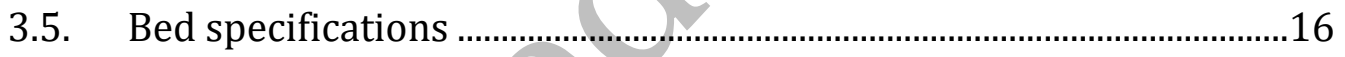

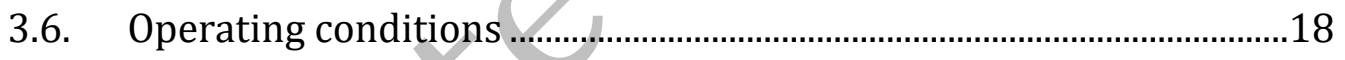

4. AHP development challenges …......................................................................19

4.1. The physical model for the entire AHP system...................................20

4.2. On the adsorbent-adsorbate working pair.............................................21

4.3. Regeneration of the adsorbent material ................................................22

4.4. How to improve an AHP system performance?...................................23

4.4.1. Adsorbent physical and thermodynamic properties ...................23

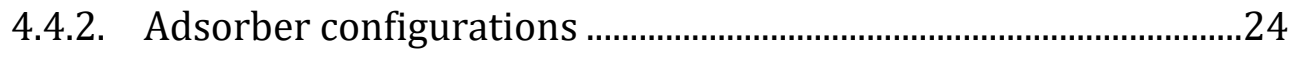

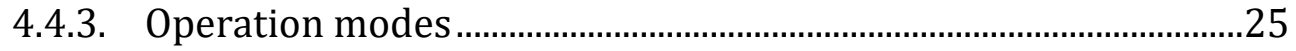

4.5. What are the system's major limitations? ...............................................26

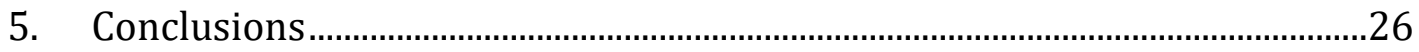

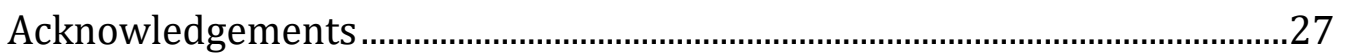

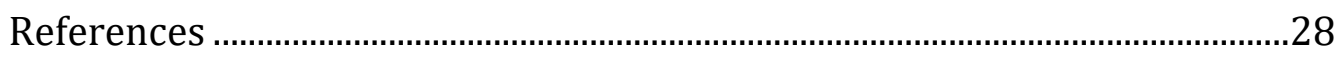




\section{Nomenclature}

$\begin{array}{ll}\mathrm{C} & \text { Specific heat } \\ \mathrm{C}_{\mathrm{p}} & \text { Constant pressure specific heat } \\ \mathrm{H} & \text { Enthalpy } \\ \mathrm{M} & \text { Mass } \\ \mathrm{P} & \text { Pressure } \\ \mathrm{Q} & \text { Heat } \\ \mathrm{T} & \text { Temperature (absolute) } \\ \mathrm{X} & \text { Adsorbate concentration in the adsorbent (uptake) }\end{array}$

Subscripts

a

Adsorbate

ads

Adsorption

bed

Adsorbent bed

C

Condenser /Cooling

cyc

Cycle

des

Desorption

e

Evaporator

$\mathrm{h}$

Heating

ic

Isosteric cooling

ih

Isosteric heating

S

Adsorbent

V

Vapour/Vaporization

Greek letters

$\tau$

Time 


\section{Introduction}

Due to their low environmental impact, adsorption heat pumps (AHPs) have attracted researchers and heating market attention over the last years. Compared to the conventional vapour compression heat pumps, which rely on high global warming potential (GWP) refrigerants (HFCs and HCFCs), AHPs may work with natural refrigerants that have zero GWP such as water and ammonia [1]. Moreover, contrary to the vapour compression heat pumps that run on electrical energy, AHPs can make mainly use of waste heat and renewable energies like solar and geothermal energy [2].

Nowadays, almost 50\% of Europe's energy consumption is channelled to heat and cold production. More than $35 \%$ of the overall consumption is used by the building sector alone, from which $75 \%$ is employed on domestic hot water production and room heating [3]. Since most of this energy is from non-renewable and environmentally harmful energy sources, AHPs can significantly contribute to decrease humanity's dependence on these harmful energy sources.

AHP's application was first demonstrated by Tchernev [4] in 1976 for domestic hot water production and space heating. Since then, much research has been done in order to increase their coefficient of performance (COP), operating with lower desorption temperatures and providing continuous heating or cooling process. Finding new working pairs or enhance the existing pairs to increase the COP, the adsorption rate and to decrease desorption temperature are among the most studied subjects at the adsorbent material level. In addition, the development of more accurate and efficient numerical models, optimization of heat and mass transfer by designing of adsorbent beds and operating conditions have also been investigated [2]. However, studies of a complete AHP system considering all its aspects and components cannot be found in literature.

In the following sections, an overview of the recent studies on adsorption heat pumps with emphasis on heating applications is presented. The main objective is to identify the bridges that need to be built between the adsorption kinetics, bed designing, operating conditions and remaining system components instead of being a repertory of previous work on the field. Thus, the identification of the major challenges and setting directions for the development of future work, attempting to 
fill the existing gaps, are discussed in this review. In addition, this paper comprises information about the AHP working principle, physical models, adsorption equilibrium and kinetics of typical and new adsorbent-adsorbate working pairs, adsorbent material thermodynamic and physical properties, adsorbent bed designing and operating conditions. Overall, it can help researchers working on the field or it can be used as a guide for researchers that are new to the AHPs subject, covering the main usually dispersed information required to start developing work in AHP systems.

\section{Working principle}

Heat pumps work by extracting heat from a low temperature level and delivering it at an intermediate temperature level, driven by a third energy source [5]. In AHPs, this third energy source is heat from a higher temperature level source that in practice can be, for example, waste heat, gas burners, electricity, geothermal and solar energy. A simple AHP consists on an adsorbent material packed or coated on an adsorbent bed (metallic structure where the adsorbent is placed), an evaporator, a condenser, an expansion valve and a heat transfer system or fluid to provide/withdraw heat to/from the adsorbent bed. In heating applications, the evaporator makes use of a free of charge low temperature level heat source (ambient, geothermal or waste heat) to vaporize the adsorbate, which is fed to the adsorbent bed during the adsorption phase. Useful heat of adsorption is collected by the heat transfer system, normally through a heat transfer fluid (HTF). On the other hand, during desorption phase heat has to be provided to the bed in order to release the adsorbate from the adsorbent in vapour state. The adsorbate is driven through the condenser, where it condenses before returning to the evaporator. Useful heat of condensation, $\mathrm{Q}_{c}$, is released during the process. A scheme of an AHP system is presented in Fig. 1.

Fig. 1 - Schematics of a common adsorption heat pump.

The ideal thermodynamic cycle of an AHP is presented in Fig. 2 in the Clapeyron diagram. It consists of four phases, namely isobaric adsorption (1-2), isosteric heating (2-3), isobaric desorption (3-4) and isosteric cooling (4-1). 
Fig. 2 - Adsorption heat pump thermodynamic cycle. (Adapted from [2])

During the isobaric adsorption phase (1-2) the valve between the evaporator and the adsorbent bed is open and the valve between the adsorbent bed and the condenser is closed. The vaporized adsorbate is adsorbed by the adsorbent releasing heat $\mathrm{Q}_{1-2}$ in the process, which has to be removed until the bed temperature reaches $T_{2}\left(\sim T_{c}\right)$. The cycle maximum adsorbate uptake, $X_{\max }$, is achieved at the end of the phase and it is dependent on the bed pressure, which is normally at the evaporator pressure, $\mathrm{Pe}$. The heat released by the adsorbent bed during this phase can be calculated through the following equation [2]:

$$
-Q_{1-2} \approx \int_{T_{1}}^{T_{2}}\left[m_{s}\left(C_{s}+X C_{p, a}\right)+m_{b e d} C_{b e d}\right] d T-\int_{X_{\min }}^{X_{\max }} m_{s} \Delta H_{a d s} d X
$$

After the isobaric adsorption phase (1-2), the isosteric heating phase (2-3) starts. The valve between the evaporator and the adsorbent bed is closed and heat is provided to the bed. Since both bed valves are closed, the adsorbate uptake remains constant throughout this phase. The pressure inside the bed increases with temperature until it reaches the condenser pressure, $\mathrm{P}_{c}$, when the phase is terminated. The amount of heat provided during this process is given by [2]:

$$
Q_{2-3} \approx \int_{T_{2}}^{T_{3}}\left[m_{S}\left(C_{s}+X_{m a x} C_{p, a}\right)+m_{b e d} C_{b e d}\right] d T
$$

The isobaric desorption phase (3-4) follows continuing the heating process with the valve between the bed and the condenser open. The adsorbate is desorbed and flows from the bed to the condenser, where it condenses releasing useful heat of condensation, $\mathrm{Q}_{c}$. The pressure remains constant during this phase, being at the condenser pressure. When desorption temperature, $\mathrm{T}_{\text {des }}=\mathrm{T}_{4}$, is achieved the valve is closed and the next phase follows. The heat that must be provided to the bed during this phase is given by [2]: 


$$
Q_{3-4} \approx \int_{T_{3}}^{T_{4}}\left[m_{s}\left(C_{s}+X C_{p, a}\right)+m_{b e d} C_{b e d}\right] d T-\int_{X_{\max }}^{X_{\min }} m_{s} \Delta H_{a d s} d X
$$

The last phase of the cycle is the isosteric cooling (4-1). The valves between the adsorbent bed and the condenser and evaporator are closed and the temperature of the bed is lowered. The uptake remains constant during the process and the pressure inside the bed decreases along with the temperature. When the pressure drops to the evaporator pressure, $\mathrm{P}_{\mathrm{e}}$, the phase ends and the subsequent isobaric adsorption phase follows. The heat withdrawn from the bed during the isosteric cooling is [2]:

$$
-Q_{4-1} \approx \int_{T_{4}}^{T_{1}}\left[m_{S}\left(C_{s}+X_{\min } C_{p, a}\right)+m_{b e d} C_{b e d}\right] d T
$$

The required heat for the vaporization of the adsorbate in the evaporator, $Q_{e}$, taken from the low-level heat source during adsorption, and the heat of condensation, $\mathrm{Q}_{c}$, obtained during desorption phase, can be described as [2]:

$$
\begin{aligned}
& Q_{e}=m_{s} \Delta X \Delta H_{v}+\int_{T_{c}}^{T_{e}} m_{s} \Delta X C_{p, a} d T \\
& Q_{c}=m_{s} \Delta X \Delta H_{v}
\end{aligned}
$$

Although it is not the objective of an adsorption heat pump for heating applications, a cooling effect is provided by the evaporator as it withdraws heat from its surroundings.

The performance of an adsorption heat pump is usually evaluated considering its coefficient of performance and specific heating or cooling power (SHP/SCP). For heating applications, $\mathrm{COP}_{\mathrm{h}}$ is defined as the ratio of the heat released by the adsorbent bed during isosteric cooling and adsorption phases $\left(\mathrm{Q}_{4-1}+\mathrm{Q}_{1-2}\right)$, plus the heat of condensation $Q_{c}$, to the heat required during isosteric heating and desorption $\left(\mathrm{Q}_{2-3}+\mathrm{Q}_{3-4}\right)$. For cooling purposes, $\mathrm{COP}_{\mathrm{c}}$ is the ratio of the heat of evaporation to the heat provided to the bed [2]. 


$$
\begin{aligned}
& \operatorname{COP}_{h}=\frac{Q_{c}+Q_{4-1}+Q_{1-2}}{Q_{2-3}+Q_{3-4}} \\
& \operatorname{COP}_{c}=\frac{Q_{e}}{Q_{2-3}+Q_{3-4}}
\end{aligned}
$$

The SHP is obtained as the ratio of useful heat to the adsorbent mass and cycle time. SCP is simply the heat of evaporation divided by the adsorbent mass and cycle time. The specific heating/cooling power is characteristic that highly depends on the system design, allowing comparison of different system setups and designs [2].

$$
\begin{aligned}
& S H P=\frac{Q_{c}+Q_{4-1}+Q_{1-2}}{m_{s} \tau_{c y c}} \\
& S C P=\frac{Q_{e}}{m_{s} \tau_{c y c}}
\end{aligned}
$$

\section{Brief state of the art}

\subsection{Physical models and numerical methods}

Numerical models can predict the system's performance with a given accuracy without the need of an experimental setup. Additionally, system's parameters and operating conditions can be easily set. The agreement between the model outputs and the real system's performance highly depends on its assumptions, numerical accuracy and knowledge of the necessary thermodynamic and physical properties. For adsorption heat pumps, three types of modelling are normally implemented, namely thermodynamic, lumped-parameter and distributed-parameter models. Thermodynamic models are the less accurate type, disregarding heat and mass transfer kinetics inside the adsorbent bed, considering that the bed is in thermodynamic equilibrium. Since the computations are straightforward, it allows a simple and fast evaluation of the system's performance upper limit. Lumpedparameter models are concentrated models, only accounting for the heat and mass transfer between the system's components but not inside the system's components themselves. Although these models do not consider temperature or pressure 
gradients inside the adsorbent and external mass transfer resistance, some describe the internal mass transfer resistance through the linear driving force (LDF) model [6]. The LDF model usually underestimates the adsorption kinetics [7]. The most accurate type of models are the distributed-parameter model. However, these models are computationally expensive since they involve solving coupled partial differential equations' systems. Nevertheless, in order to obtain accurate predictions for the system's performance the distributed-parameter models are essential. Normally, LDF model is used for the intra-particle mass transfer resistance whereas the inter-particle mass transfer resistance is described by Darcy's Law. An extensive review on numerical models for adsorption heat pump modelling can be found in [8]. The most common methods for numerically solving the physical model equations are alternating difference implicit (ADI), finite difference, CrankNicholson and Runge-Kutta methods. The method of lines is commonly used to transform the partial differential equations' systems into a system of ordinary differential equations by discretizing the spatial coordinate.

\subsection{Adsorption equilibrium}

Concerning the adsorption equilibrium, there are four equations that are commonly used: Dubinin equations (normally Dubinin-Astakhov equation), Langmuir equation, Freundlich equation and Toth equation. An extensive description of the adsorption equilibrium theory and equations is presented in [9]. Recently, a comparison between several adsorption equations predictions and experimental data was made for the AQSOA zeolite-like adsorbent [10]. Accordingly to the IUPAC (International Union of Pure and Applied Chemistry) [11] the equilibrium isotherms can be classified in six types (Type I - Type VI) and are presented in Fig. 3. Type IV and Type V isotherms show a hysteresis, which is presented by red and blue lines for adsorption and desorption, respectively. For AHP applications an S-shaped isotherm represents a major advantage since the majority of the adsorbate uptake occurs for low relative pressures [12]. For the adsorption kinetics, the LDF (Linear Driving Force) model was proven to be a valid tool to describe the evolution of the adsorption uptake in time $[13,14]$, being used in almost all simulation models. 
Fig. 3 - Types of adsorption isotherms according to the IUPAC classification. In Type IV and Type V graphs, the red and blue lines represent adsorption and desorption,

respectively. (Adapted from [11]).

\subsection{Adsorbent-adsorbate working pairs}

Much work has been done and still is being done aiming to characterize and compare adsorbent-adsorbate working pairs, normally using typical operating conditions $[2,3,15-20]$. Concerning the adsorbate, water is by far the most used but ammonia, methanol and ethanol. Ammonia is commonly used with activated carbon adsorbents, having a high specific heating power due to the high pressure during the adsorption phase. On the other hand, in case of leakage it is toxic and releases an intense smell. Ethanol and methanol are mostly used for refrigeration applications due to their low vaporization temperature [16].

The typical adsorbent materials used for AHPs are zeolites, silica gels, activated carbons and zeolite-like AIPOs (aluminophosphates) and SAPOs (silicoaluminophosphates). The adsorbent-adsorbate pair selection is one of the key issues for a reliable adsorption heat pump. Although many studies have been conducted on working pairs, most consider only the adsorbate and adsorbent material kinetics and performances, disregarding its applicability in a practical or commercial system. Many working pairs with excellent adsorption capacity have been reported recently, however, most of them still possess low hydrothermal stability or show hysteresis associated to the material aging over few cycles. Another aspect is the material readiness to market since even though some adsorbent materials show good uptake capacity, hydrothermal stability and long life cycle time, they cannot be produced in mass scale or the cost for their production is unsustainable.

\subsubsection{Silica gel}

Silica gel is a classical water adsorbent that has been studied and implemented in several adsorption systems over the last years. The advantages of silica gel adsorbents are the low regeneration temperatures $\left(60-100{ }^{\circ} \mathrm{C}\right)$, low cost and reliability in practical applications [18]. Unfortunately, most of the water adsorption occurs at high relative pressures. Many alternatives to overcome this problem have been investigated, namely the increase of silanol groups on the surface and the 
reduction of the pore size. The alternative with the most water adsorption capacity is the mesoporous silica containing impurities, such as aluminium or other metals [21].

\subsubsection{Zeolites}

Although zeolites can be combined with many refrigerants water is undoubtedly the most common. Similar to silica gel, zeolites have been the most studied adsorbents and implemented on experimental systems. The water uptake capacity of the zeolites is relatively high, as well as its adsorption heat. On the other hand, a high desorption temperature (200-300 ${ }^{\circ} \mathrm{C}$ for natural zeolites) represents a major setback for the use of zeolites as adsorbent material on adsorption heat pumps. Some improvements with the objective of reducing the desorption temperature have been made over the years [18,21].

\subsubsection{AIPO and SAPO}

AIPOs (aluminophosphates) and SAPOs (silico-aluminophosphates) are zeolitelike materials that possess high water uptake capacity and are capable of working with low desorption temperatures $\left(60-100{ }^{\circ} \mathrm{C}\right)$. These materials have S-shaped isotherms meaning that they have a high water exchange capacity for low temperature differences [18,21,22]. Recently, Mitsubishi Plastic Inc. developed and commercialized new adsorbent materials, AQSOA ${ }^{\circledR}$-FAM-Z01 and AQSOA ${ }^{\circledR}$-FAMZ02 [23,24]. Both materials work with desorption temperatures in the range of $60-90^{\circ} \mathrm{C}$ and seem to be a promising solution for heating applications.

\subsubsection{Activated carbons}

Activated carbons have been widely implemented with methanol and ammonia as adsorbate. They can be used in the form of powder, fibre, granular, compact and monolithic carbon. The temperature ranges for the activated carbons are very wide and depend on its form and on the used adsorbate. An extensive study on activated carbons was performed in [25].

\subsubsection{Composite adsorbents}

The composite adsorbents are normally formed by inorganic salts inserted in porous matrices. These adsorbents can be combined with water, methanol, ethanol or ammonia as the adsorbate $[18,26]$. Some of these materials, based on mesoporous 
silica impregnated with $\mathrm{CaCl}_{2}$ (SWS-1L) and $\mathrm{LiBr}$ (SWS-2L), possess a high water uptake $(0.75 \mathrm{~kg} / \mathrm{kg})$ and a relatively low desorption temperature $\left(70-120{ }^{\circ} \mathrm{C}\right)$ [27]. The composite SWS-8L allows a water uptake of $0.2 \mathrm{~kg} / \mathrm{kg}$ and an even lower desorption temperature $\left(75-80{ }^{\circ} \mathrm{C}\right)$ [28]. As for the utilization of methanol and ethanol as adsorbate, some studies can be found in references [29-31].

\subsubsection{Metal-Organic frameworks (MOFs)}

Although MOFs demonstrate a high water, ethanol and methanol uptake capacity under common operating conditions, their hydrothermal instability, degradation over time and high cost are still some major obstacles [18]. Nevertheless, accordingly to recent studies like reference [32], MOFs are very promising materials for future use as adsorbents. In order to implement these materials on practical systems, improvements must be made to their hydrothermal stability and hysteresis behaviour.

New materials are being investigated every day and some are very promising for future applications, namely composite adsorbents and MOFs (Metal Organic Frameworks) [32-39]. Although some of these adsorbents demonstrate very good uptake capacities, they also show hydrothermal instability, degradation over time and high cost, which are still some major obstacles [18]. Furthermore, they are difficult to produce in a large scale, which makes them still not suitable nor available for final applications that require mass production.

Some recent reviews include a summary of the research done on adsorption materials [2,16]. Recently, Boman et al. [22] performed a screening of potential working pairs for AHPs based on the thermodynamic and transport characteristics. In addition to the working pairs comparison, an extensive list of more than one hundred adsorbent-adsorbate uptake equations are listed and referenced, serving as a useful database for future research [22].

\subsection{Adsorbent physical and thermodynamic properties}

In order to obtain a system with reasonable SHP, efforts have to be done to lower the heat and mass transfer resistances. These parameters depend on the adsorbentadsorbate pair and the bed design (i.e. adsorbent thickness, use of thermal enhancing material between adsorbent and bed structure, fins configuration, etc.). 
Poyelle et al. [40] investigated the effect of the convective heat transfer coefficient and adsorbent permeability on the COP for cooling mode ( $\left.\mathrm{COP}_{c}\right)$ and SCP (Specific Cooling Power) of an adsorptive air conditioning unit. A high conductive adsorbent composite was developed and implemented in an adsorber, resulting on considerable improvements of the effective thermal conductivity and convective heat transfer coefficient, respectively, when compared to a common zeolite granular bed. However, the effective permeability is decreased from $10^{-9} \mathrm{~m}^{2}$ to $10^{-12} \mathrm{~m}^{2}$ due to material consolidation, increasing the mass transfer resistance. Experimental tests were performed for different evaporation temperatures, $\mathrm{T}_{\mathrm{e}}$. For $\mathrm{T}_{\mathrm{e}}=4^{0} \mathrm{C}$ the mass transfer resistance dictates the system performance whereas for $\mathrm{T}_{\mathrm{e}}$ in the range of $25-30{ }^{\circ} \mathrm{C}$ the performance is controlled mostly by the heat transfer resistance inside the adsorbent, resulting on a gain of 0.27 and $38 \mathrm{~W} / \mathrm{kg}$ for the $\mathrm{COP}_{\mathrm{c}}$ and SCP, respectively. This enhancement is a consequence of the pressure raise in the adsorber inherent to the increase of $\mathrm{T}_{\mathrm{e}}$, which accelerates the adsorption process. An analogous analysis for the condenser temperature, $\mathrm{T}_{c}$, was not reported but if the same dynamics take place in desorption process, if $\mathrm{T}_{\mathrm{c}}$ increases the process duration will probably increase also, penalizing the performance.

Zhang et al. [41] presented a parametric study on heat and mass transfer dynamics of an adsorption cooling system for automobile applications, resorting on waste heat from the exhaust gas to regenerate the adsorbent. The effects on the system performance, based on finite difference computational simulations, were the objective of their research. Simulations indicated that if the adsorbent permeability is beneath a critical point value of $5 \times 10^{-11} \mathrm{~m}^{2}$ the system's performance severely decreased. In addition, a strong influence of the heat transfer coefficients and bed thickness on the performance was noticed. Increasing the bed thickness will decrease the heat transfer and consequently decrease the system's performance. Finally, they also reported that for systems with short cycle times the internal mass transfer resistance can be limiting.

Restuccia et al. [42] demonstrated that there is a commitment between the heat and mass transfer in the adsorbent. Four shapes of zeolite were used as adsorbent: grains, brick, powder and coated layer. Using a numerical model and a Yate's analysis to the data, a comparison based on the specific cooling power was done. Results showed that the parameters that mostly affect the system's performance are 
the bed permeability and thickness. Furthermore, although increasing the adsorbent material consolidation will increase the heat transfer coefficients, the permeability will decreases, which means that a balance between these parameters is needed to maximize the system's specific power. This effect was demonstrated in this study since grain (lowest heat transfer coefficient and highest permeability) and brick (lowest permeability and higher heat transfer coefficients) shaped adsorbent beds showed worse performance than the powder adsorbent bed (medium permeability and heat transfer coefficients). In addition, since the system's bed thickness also influences the heat and mass transfers, it strongly influences the system's performance. This effect makes the zeolite coating (lower thickness) the adsorbent configuration that has the best performance.

Pinheiro et al. [38] presented a study of an adsorption heating system based on the ETS-10- water pair. The developed model accounts for the adsorption equilibrium, heat and mass transfer in one dimension, heat transfer between the vapour and the adsorbent and intra-particle mass transport. Heat transfer resistances in the adsorbent material and adsorbent bed interface, as well as between the heating/cooling fluid and the adsorbent bed were neglected. Their research demonstrated that by decreasing the adsorbent thickness, the SHP increases and the COP slightly decreases. Furthermore, the system COP reaches its maximum when the HTF temperature is equal to the temperature at the end of the isobaric desorption. In fact, the HTF temperature should be higher than the desired regeneration temperature since heat loss occurs in the metal/adsorbent interface, which was disregarded in this model.

Since adsorbent coatings seem to be the best configuration for AHPs [42], it is important to study their hydrothermal and mechanical stabilities. This was done by Freni et al. [43] using experimental methods on zeolite-based (AQSOA-Z02 from Mitsubishi Plastics) coatings over aluminium substrates, manufactured by the Institute for Advanced Energy Technologies of the Italian Research Council (CNR-ITAE) using the dip coating technique. The manufactured coating was compared with a coating prepared by Mitsubishi Plastics (MP) and the hydrothermal stability was successfully verified after 35000 cycles, for both adsorbents. Concerning the mechanical strength, it was found that for the MP coating it is already satisfying. On the other hand, the CNR-ITAE coating still needs 
to be improved to achieve satisfactory mechanical stability. In [10], detailed data about the AQSOA type zeolites is presented.

A comparison between a coated and a granular adsorbent was performed in [44] using a SAPO-34 zeolite. The comparison was based on the differential water loading, mass SCP $\left(\mathrm{W} / \mathrm{kg}_{\mathrm{s}}\right)$, volumetric SCP (VSCP) $\left(\mathrm{W} / \mathrm{dm}^{3} \mathrm{~s}\right)$ and COP. The coated adsorber presented higher differential water loading, mass SCP, and lower volumetric SCP (VSCP) and COP. The difference on the $\mathrm{COP}_{c}$ is due to the higher metal to adsorbent mass ratio of the coated adsorber, which has to be decreased to obtain better $\mathrm{COP}_{c}$.

A three-dimensional coupled heat and mass transfer numerical model was proposed by Radu et al. [45] to study the effects of different adsorbent particle sizes and packing configurations. Their work suggest that particles with smaller diameters and configurations with fewer layers present faster sorption kinetics. Desorption phase was proven faster than adsorption by the numerical model since it occurs at a higher temperature, resulting in faster diffusion. As previously stated by other works, it was also concluded that a small adsorbent bed thickness leads to better performance.

Girnik et al. [46] used a binder on a commercial active carbon to enhance the adsorption kinetics. The volumetric large temperature jump (V-LTJ) method was used to measure the adsorbate amount in the adsorbent. It was also demonstrated that for smaller particle sizes the performance is bettered due to faster ad/desorption dynamics. Ramji et al. [47] used a CFD (Computational Fluid Dynamics) model to study the effect of the adsorber external wall thickness, which affects the capacity of the adsorber to maintain the optimum temperature during the desorption phase. The CFD model results were compared to experimental data and a good agreement was achieved. The results suggest the optimal thickness of the stainless steel wall for the adsorber external wall.

\subsection{Bed specifications}

Several studies have been conducted aiming at the modelling and experimental testing of adsorbent bed/heat exchanger configurations. The common parameters investigated are flat or circular tube configurations, the use of fins, fin height, fin pitch and number of fins. Núñez et al. [48] developed a prototype of an adsorption 
chiller and heat pump for domestic applications capable of delivering a nominal power of $3-8 \mathrm{~kW}(\mathrm{COP}=0.5)$ and $16 \mathrm{~kW}(\mathrm{COP}=1.5)$ for cooling and heating modes, respectively. However, to achieve this power level two beds of silica gel with $35 \mathrm{~kg}$ were used, corresponding to SCP of 86-229 W/kg and SHP of $457 \mathrm{~W} / \mathrm{kg}$. As a result, a big machine that might not be adequate for domestic applications is needed. Therefore, further improvements should be made to the bed design in order to maximize the heat and mass transfer kinetics that were disregarded in this study.

Kowsari et al. [49] presented a parametric study of a heat exchanger (HEx) to be used as adsorbent bed using a numerical model, which was validated with an experimental set up. Rectangular and trapezoidal bed geometries were explored using different fin heights and pitch and the results were compared based on SCP, VSCP, $\mathrm{COP}_{c}$, adsorbent mass and metal mass. The rectangular geometry showed the best SCP when compared to a similar configuration for the trapezoidal geometry. As reported by previous studies, higher metal mass leads to a lower $\operatorname{COP}_{c}$ and large adsorbent thickness provides poor SCP.

Rivero-Pacho et al. [50] performed a parametric study of a carbon-ammonia adsorber for a gas fired AHP operating under room heating conditions, using two 2-D finite difference simulation models programmed in Matlab ${ }^{\mathrm{TM}}$. The adsorber is made of 1700 tubes with $1.2 \mathrm{~mm}$ outer diameter and a pitch of $3 \mathrm{~mm}$, with a mixture of carbon grains and powder packed between the tubes. A finned tube and shell and tube geometries were compared and no major differences in the COP were reported. However, according to the authors by using the finned tube geometry the number of tubes can be decreased seven times, reducing the manufacturing costs.

A novel adsorber structure with aluminium sintered metal fibres was reported by Wittstadt et al. [51]. Results obtained by a driving temperature difference analysis showed that this new type of HEx reaches a very high volume specific power density for a reasonable adsorbent to HEx mass ratio.

Graf et al. [52] presented an experimentally calibrated dynamic model to predict the SCP and COP of AHPs. Gravimetric large temperature jump (G-LTJ) experiments were conducted on a representative adsorber part in order to calibrate the adsorber model, which is then used to simulate an AHP and predict its SCP and COP. The heat and mass transfer coefficients were determined by least-square fitting the measured and simulated adsorbate uptake. The model was validated for a small representative 
adsorber part, allowing a fast evaluation of design and operating parameters, such as fin geometry, cycle times and operating temperatures. However, the model was not validated for a real AHP system and the question of whether it successfully predicts the performance of a real sized adsorber remains. References $[53,54]$ describe the designing and testing of AHP systems based on previous parametric analysis of single system components. These approaches are purely experimental and provide accurate characterizations of a system for a given experimental scenario. However, these kind of experimental approaches are limited to the implemented setup, making it difficult to perform a parametric analysis of the entire system since the whole setup would have to be dismantled and built over again in order to change some parameters.

\subsection{Operating conditions}

Sapienza et al. [55] developed an adsorption chiller prototype with three flat tube HExs coated with the AQSOA-Z02 adsorbent and simultaneously packed with silica gel grains. The prototype was tested in a test bench for adsorption chillers at CNR-ITAE Testing Centre under two different operating temperatures sets. The temperatures of the evaporator and condenser in/outlet were monitored and the effect of the cycle time on the average cooling power (ACP) and $\mathrm{COP}_{c}$ was investigated for the two different working conditions. The cycle times that result in maximum ACP were identified as well as the cycle times that lead to maximum COP. The results show that maximum ACP and maximum $\mathrm{COP}_{c}$ cannot be obtained simultaneously and the balance between them can be controlled by adjusting cycle times.

An experimental study of an adsorption heat storage system using AQSOA-Z02water pair was presented by Palomba et al. [56]. The system was tested under different operating conditions for cold storage, daily heat storage and seasonal heat storage working modes. The temperatures in the adsorber, evaporator and condenser in/outlets were monitored. The results demonstrated that desorption temperature is the parameter with higher repercussions on the storage capacity of the system. Furthermore, the evaporator temperature has a significant influence on the system's performance while in the range of $5-10{ }^{\circ} \mathrm{C}$, having little effect for temperatures above this range. 
Dawoud [1], from Viessmann Werke Allendorf $\mathrm{GmbH}$, presented a gas-fired adsorption heat pump for heating appliance and described the system, dividing it in four modes. The concept is to use adsorption and desorption phases to sustain the low heat demand operation modes. In the medium heat demand mode, the adsorption and desorption processes can only deliver the required heat to the heating net at the beginning of each phase. To achieve the desired supply temperature, the gas burner is used to heat backup the adsorption heat pump when the adsorption and desorption phases are close to their ends. Even when the processes are close to their ends, they are still used to pre-heat the return cold water, reducing the temperature lift needed in the gas burner. When in high heat demand mode, the water is heated using solely the gas burner. The system was implemented in two one-family houses in Germany and showed 27\% more efficient seasonal gas utilization, which results in $20 \%$ less $\mathrm{CO}_{2}$ emissions when compared to the stand-alone gas condensing boiler technology. As a result, Viessmann has launched a commercial product called Vitosorp 200-F. The heat pump adsorption module is composed by a HEx coated with zeolite adsorbent and it is regenerated by a water circuit heated by a gas-fired boiler. However, Vitosorp 200-F remains a confidential solution and detailed information about it is not available. A performance-predicting model, which can provide designing and dimensioning details to guide in the construction of a similar system, does not exist or is unavailable to outsiders. Furthermore, the system's components are not specifically described, which makes it impossible to develop a physical model that represents the system.

\section{AHP development challenges}

Although several studies on the adsorption kinetics, adsorbent bed specifications and operating conditions are reported in literature, a system-level approach considering an entire AHP system would be a valuable contribution towards the development of the AHP technology. The optimization of a single or few parameters, isolated components and working pairs can have only a slight effect on the performance of the complete system. System-level studies including simultaneously the optimization of the adsorption kinetics, adsorbent bed specifications, operating conditions and relationship between all system 
components is lacking [8]. Furthermore, detailed experimental data to allow the validation of physical dynamic models that consider an entire AHP system are still unavailable. Future research must be done to consolidate the individual optimizations into a practical and commercial AHP in order to identify and distinguish the high sensitive parameters from the more irrelevant ones.

The main challenges that are yet to be overcome in order to develop an AHP system for heating appliances are discussed below. The objective of this work is not to present concrete solutions but to identify the major challenges and make way for future work to be developed as an attempt to overcome them. Nevertheless, some ideas and possible approaches that have been considered as promising by the authors are reported.

\subsection{The physical model for the entire AHP system}

A physical model that can be used as a dimensioning and optimization tool for an AHP system for heating applications is currently inexistent or unavailable in the literature. A possible approach aiming at the development of such a tool, with the ability to describe an entire AHP system, is to consider that the adsorber module can be described by a simple transient lumped-parameter model. Although the external mass transfer resistance and the temperature gradient inside the adsorbent material are neglected, the lumped-parameter analysis can account for the internal mass transfer resistance through the LDF model. A lumped-parameter model can provide some knowledge about the system's dynamics, enabling one to make some preliminary observations. Moreover, some key parameters with influence on the system's performance can be identified by this simpler model. This kind of approach was made by Fernandes et al. $[57,58]$ to describe a thermal energy storage system with an adsorption module and perform a viability study. This methodology was proven suitable for the proposed system since its dynamics were slow enough to consider thermal equilibrium inside the adsorber. For shorter cycle times, as occurs when gas burners are used as heating elements, the equilibrium state inside the adsorber cannot be assumed blindly. A more complicated one-dimensional, bi-dimensional or tridimensional distributed-parameter analysis of the adsorber module needs to be considered. By comparing the results from both approaches, assuming that the tri-dimensional distributed-parameter model as the exact solution, the accuracy of the lumped-parameter model can be verified for different operating modes/conditions. 
Finally, after the physical model of the adsorber module is consolidated it has to be interconnected with the remaining system's components resulting in a tool capable of describing an AHP system as a whole.

A possible hypothesis for the development of a physical model for a complete AHP system is to use the type of models referred in the previous paragraph to describe an element that can be representative of an adsorber module. A possible adsorber module can be made by several metal tubes coated with an adsorbent material enclosed in a chamber that is connected to the evaporator and the condenser. The heat transfer fluid is circulated inside the metal tubes, providing/withdrawing heat to/from the adsorbent material. By circulating the heat transfer fluid inside the metal tubes where the coating exists in their outer surface, the only heat transfer is to the adsorbent material, which is an advantage when compared to other designs where the heat transfer fluid circulates on an outer shell with the adsorbent material packed inside. A possible adsorber module and its representative element are presented in Fig. 4. A distributed-parameter model considering the radial and axial directions should be sufficient to model the purposed adsorber since it is essentially symmetric along the angular direction. The schematics of the representative element for the development of a physical model is presented in Fig. 5.

Fig. 4 - Adsorber module (on the left) and its representative element (on the right).

Fig. 5 - Schematics of the representative element for the development of physical models.

\subsection{On the adsorbent-adsorbate working pair}

As previously stated in this paper, there are several adsorbent-adsorbate working pairs that can be used in an AHP system for heating applications. However many of these working pairs are not available in the amounts needed for application in a real size AHP or their cost is unsustainable. From the available literature, the following adsorbent-adsorbate working pairs show interesting characteristics and readiness to market for being used in a real AHP system for heating applications: 
$\checkmark$ Activated carbon - Ammonia

$\checkmark$ Zeolite 4A-Water

$\checkmark$ Zeolite $13 \mathrm{X}$ - Water

$\checkmark$ AQSOA-Z02-Water

These are the most studied working pairs and there is much information about the adsorbent physical and thermodynamic properties. Furthermore, hydrothermal stability and material aging for these few particular materials are already well established and considered suitable. Thus, these working pairs are the safest options for usage in an AHP system for heating appliances. Furthermore, the emphasis that is currently being made by the industry on environmentally friendly systems makes the usage of water as adsorbate very desirable.

\subsection{Regeneration of the adsorbent material}

There are several ways of regenerating the adsorbent material being the most common solar thermal energy, waste heat and gas burners. Waste heat is normally used in applications where it is abundant at low cost, such as industrial processes or thermal engines. However, for domestic applications it is normally unavailable in a useful amount. Solar thermal energy is commonly used for adsorption heat storage, which can store energy during the day. However, these systems just regenerate the material when solar energy is available, storing heat of adsorption to be used later. In order to control the cycle time, the adsorbent material must be regenerated whenever the system requires, which varies for different operating conditions and system's configuration. Gas burners can be used anytime, providing a solution for cycle time control. Unfortunately, unlike solar energy, natural gas is not free and releases $\mathrm{CO}_{2}$ to the atmosphere. A combination of the two technologies might be a good solution since by using solar energy when it is available and the gas burner only when the solar energy is unavailable or it is not self-sufficient. Therefore, the operational costs and $\mathrm{CO}_{2}$ emissions inherent to the burning of natural gas can be lowered while maintaining the cycle time control. In addition, the gas burner can be directly used to provide heat when the heat power demands are too high to be satisfied by the adsorption process alone. It can also be used to elevate the temperature effectively over $50{ }^{\circ} \mathrm{C}$, which is very difficult to achieve through the adsorption process. 
The usage of electricity for water heating has recently captured the market's interest [59], as it can be obtained from renewable energy sources. Using electricity for the adsorbent material regeneration still requires future investigation, comparing it to the common adsorbent regeneration options in order to identify its advantages and disadvantages.

\subsection{How to improve an AHP system performance?}

Three main areas can be improved in order to better an AHP system performance, which are adsorbent material physical and thermodynamic properties, adsorber configuration and operating modes.

\subsubsection{Adsorbent physical and thermodynamic properties}

Regarding the adsorbent material physical and thermodynamic properties, the simultaneous enhancement of the adsorbent material permeability and thermal conductivity would be a major improvement. However, from reference [40] it is concluded that by improving one of these parameters the other is deteriorated. Finding the right balance between these two parameters comprises a good chance of improving the system's performance. Furthermore, the convective heat transfer coefficient between the adsorber metal wall and the adsorbent material directly influences the heat flux that is transferred between them, hardly affecting the cycle time and consequently the SHP. This parameter is influenced by the effective contact between the adsorbent material and the adsorber metal wall. In order to enhance the effective contact better coating techniques that bind the adsorbent material to the metal wall without compromising the adsorbent permeability can contribute to the system's performance improvement. All these parameters are currently being developed at lab scale but their sustainable production for the market is still a challenge.

Larger contact areas between the adsorbent material and the adsorber metal wall will enhance the heat transfer between them. In order to increase this heat transfer area it is common to include fins in the adsorber. However, it is also common to disregard the adsorber metal mass in the performance calculation, which needs to be taken into account in the physical models to obtain accurate results. Recent studies $[18,19]$ have demonstrated that the metal to adsorbent material mass ratio affects the performance of AHP systems. Higher metal to 
adsorbent mass ratios lead to lower performances, which was verified for several working pairs. Thus, by using an adsorber configuration with fins with the objective of enhancing the heat transfer in the bed the metal to adsorbent mass ratio is considerably increased. The added fins will not only increase the total metal mass but also occupy precious space that could be otherwise filled with adsorbent material, lowering the adsorbent mass when compared to a similar configuration without fins.

\subsubsection{Adsorber configurations}

There are several packing techniques and adsorber configurations such as shell packing, which was used in Ref. [3], plate-finned, tube, finned tube, fin plate, flat pipe, spiral plate and coated tube, which are described in Ref. [60]. All the different configurations result in different adsorbent-metal wall contact areas, metal to adsorbent mass ratios, adsorbent area exposed to the adsorbate and heat losses to the environment. As result, a lot of work as to be done in order to select the best adsorber configuration, which may be different for each application and dependent on the adsorber metal and adsorbent-adsorbate working pair thermodynamic and physical properties. For example, shell configuration has less adsorbent-adsorbate contact area but it has more adsorbent-metal contact area when compared to the tube configuration. Nevertheless, in the shell configuration the HTF circulates around the adsorbent material whereas in the tube configuration the adsorbent material is packed around the tube, which will minimize heat losses since the heat can only be transferred from the tube to the adsorbent material. Finned HExs will have more adsorbent-metal contact area but will have less adsorbent-adsorbate contact area and higher metal to adsorbent mass ratio. When designing an adsorber one should take into account the following aspects: maximization of the heat transfer between adsorbent material and the heat transfer fluid, maximization of the adsorbent surface exposed to the adsorbate, minimization of the metal to adsorbent mass ratio, guarantee of a good thermal contact between the adsorbent bed and the metal (for example using thermal interface material paste), and keep a simple design that can be built using vacuum technology elements. Selecting the best configuration and designing the optimum adsorber is a hard task, requiring further investigation aiming at the best balance of all these parameters. 


\subsubsection{Operation modes}

The operation mode of an AHP system will influence the system's performance and the best operation mode for one application is not necessarily the best for different applications. Deciding how to use the system and selecting the best operation mode for a given application can be challenging. As previously mentioned, [1] presents four different working modes for a specific heating appliance. For example, in case of an integration with a solar panel it could be used during the day to regenerate the adsorbent and after, directly heat the water in a tank, storing sensible heat in the water tank and adsorption heat in the adsorbent material that can both be used later. The AHP system can be used as a heat storage system by using high adsorbent mass and long cycle times, which can be advantageous if the energy source driving it is available or cheaper during a given time period. On the other hand, if the application requires high powers it might be a best option to define an operation mode that results in faster/shorter cycles.

A possible system configuration is presented in Fig. 6. This system uses the adsorber module from Fig. 4 to heat the water inside the water tank. The water is used as heat transfer fluid and a gas burner is used for the adsorbent regeneration. Thus, the major components of the system are the adsorber module, evaporator, condenser, gas burner, expansion valve (EV) and the water tank.

Fig. 6 - Possible AHP system schematics.

During the adsorption phase, the adsorber is receiving adsorbate vapour coming from the evaporator and the valve to the condenser is closed. As the adsorbent material uptakes the adsorbate, heat of adsorption is released. In order to retrieve this heat, cold water is taken from the bottom of the water tank, or from the supply network, and circulated inside the tubes of the adsorber. After leaving the adsorber, the warmed water is returned to the tank. The process continues until a predetermined uptake value is achieved or a certain time is passed. Afterwards, desorption process starts and water is taken from the water tank, heated by the gas burner and circulated inside the tubes of the adsorber. The adsorbent material releases the adsorbate, which circulates through the condenser releasing the heat of condensation to the water inside the tank. The process continues until a predetermined uptake value is achieved or a certain time is passed. At the end of the 
desorption phase, the hot water that was circulated inside the tubes of the adsorber is returned to the water tank.

This system can work in three different modes: low power demand, medium power demand and high power demand. In the low power demand mode, the gas burner is only used to regenerate the adsorbent material and the heat delivered to the water tank is solely obtained by the adsorption and regeneration processes. In the medium peak demand mode, the gas burner is used not only for the regeneration of the adsorbent but also to heat the water the leaves the adsorber during the adsorption process, boosting its temperature to a higher level. Finally, in the high power demand mode the system works as a gas boiler, using the gas burner to heat the water directly, providing instant hot water.

\subsection{What are the system's major limitations?}

An AHP system has some limitations, some easier to overcome than others. The major limitations that have been identified are the following:

- Low COP;

- A large mass of adsorbent material is needed to produce the required heating powers for most applications;

- The materials used in the system (valves, joints, welding, etc.) need to be adequate for vacuum operating conditions;

- Difficult to provide heat at temperatures over $55^{\circ} \mathrm{C}$;

- The adsorbent-adsorbate working pairs with higher COP and capable of delivering higher heating powers require high regeneration temperatures;

- Many cautions have to be taken when regeneration temperatures higher than the heat transfer fluid's boiling temperature are used due to the possible resulting high pressure inside the pipes.

\section{Conclusions}

A review on AHP systems with emphasis on heating applications was presented. The most relevant studies in the field are reported and the major gaps in the literature were identified and discussed. The essential subjects to the understanding of an AHP namely its working principle, physical models, adsorption equilibrium 
and kinetics of typical and new adsorbent-adsorbate working pairs, adsorbent material thermodynamic and physical properties, adsorbent bed designing and operating conditions were discussed. Overall, a help to researchers working on the field or a guide for new researchers approaching the AHP subject was presented, highlighting the hindrances and work that still has to be done in order to develop a physical model and an optimized solution for an AHP system.

Despite all the research performed on new adsorbent-adsorbate working pairs, not many are ready to market, easily accessed and produced, hydrothermal stable and with a long life cycle. A bridge between the material's level and system's level studies is yet to be built. The LDF model and Darcy's Law are the most common models to account for the internal and external mass transfer resistances, respectively.

A physical model that considers a whole AHP system cannot be found in the literature. Many experimental studies and numerical simulations do not provide detailed information that can be used to validate new models. Furthermore, simultaneous optimization of the bed specifications, operating conditions and adsorbent material thermodynamic and physical properties is not reported in the literature. The development of a physical model that describes an entire AHP system would be welcome. In addition, adsorbent-adsorbate working pairs with low heat and mass transfer resistances, which can regenerated at lower temperatures would be ideal for the most applications. New operating modes that can improve the performance of the entire AHP system are valuable towards achieving competitive AHP solutions.

\section{Acknowledgements}

The present study was developed in the scope of the Smart Green Homes Project [POCI-01-0247-FEDER-007678], a co-promotion between Bosch Termotecnologia S.A. and the University of Aveiro. It is financed by Portugal 2020 under the Competitiveness and Internationalization Operational Program, and by the European Regional Development Fund. 


\section{References}

[1] Dawoud B. On the development of an innovative gas-fired heating appliance based on a zeolite-water adsorption heat pump; System description and seasonal gas utilization efficiency. Appl Therm Eng 2014;72:323-30. doi:10.1016/j.applthermaleng.2014.09.008.

[2] Demir H, Mobedi M, Ülkü S. A review on adsorption heat pump: Problems and solutions. Renew Sustain Energy Rev 2008;12:2381-403. doi:10.1016/j.rser.2007.06.005.

[3] Pinheiro JM, Salústio S, Rocha J, Valente AA, Silva CM. Analysis of equilibrium and kinetic parameters of water adsorption heating systems for different porous metal/metalloid oxide adsorbents. Appl Therm Eng 2016;100:21526. doi:10.1016/j.applthermaleng.2016.01.142.

[4] Tchernev DI. Solar app. of natural zeolites. In: Mumpton LBS and FA, editor. Proc. Nat. Zeolites Oc. Prop. Use, Oxford: Pergamon Press; 1976.

[5] Ulku S. Adsorption heat pumps. J Heat Recover Syst 1986;6:277-84. doi:10.1016/0198-7593(86)90113-X.

[6] Sircar S. Linear-driving-force model for non-isothermal gas adsorption kinetics. J Chem Soc Faraday Trans 1 Phys Chem Condens Phases 1983;79:785. doi:10.1039/f19837900785.

[7] Chahbani MH, Labidi J, Paris J. Effect of mass transfer kinetics on the performance of adsorptive heat pump systems. Appl Therm Eng 2002;22:2340. doi:10.1016/S1359-4311(01)00067-9.

[8] Pesaran A, Lee H, Hwang Y, Radermacher R, Chun HH. Review article: Numerical simulation of adsorption heat pumps. Energy 2016;100:310-20. doi:10.1016/j.energy.2016.01.103.

[9] Hassan HZ, Mohamad AA, AlyousefY, Al-Ansary HA. A review on the equations of state for the working pairs used in adsorption cooling systems. Renew Sustain Energy Rev 2015;45:600-9. doi:10.1016/j.rser.2015.02.008.

[10] Teo HWB, Chakraborty A, Fan W. Improved adsorption characteristics data for AQSOA types zeolites and water systems under static and dynamic conditions. Microporous Mesoporous Mater 2017;242:109-17. doi:10.1016/j.micromeso.2017.01.015.

[11] Sing KSW. Reporting physisorption data for gas/solid systems with special reference to the determination of surface area and porosity (Recommendations 1984). Pure Appl Chem 1985;57:603-19.

[12] Ehrenmann J, Henninger SK, Janiak C. Water adsorption characteristics of MIL-101 for heat-transformation applications of MOFs. Eur J Inorg Chem 2011:471-4. doi:10.1002/ejic.201001156.

[13] Sircar S, Hufton JR. Why does the Linear Driving Force model for adsorption kinetics work? Adsorpt Int Adsorpt Soc 2000;6:137-47. doi:10.1023/a:1008965317983.

[14] Sakoda A, Suzuki M. Fundamental study on solar powered adsorption cooling system. J Chem Eng Japan 1984;17:52-7. doi:10.1252/jcej.17.52.

[15] Wang LW, Wang RZ, Oliveira RG. A review on adsorption working pairs for refrigeration. Renew Sustain Energy Rev 2009;13:518-34. doi:10.1016/j.rser.2007.12.002.

[16] Cabeza LF, Solé A, Barreneche C. Review on sorption materials and technologies for heat pumps and thermal energy storage. Renew Energy 
2017;110:3-39. doi:10.1016/j.renene.2016.09.059.

[17] Goyal P, Baredar P, Mittal A, Siddiqui AR. Adsorption refrigeration technology - An overview of theory and its solar energy applications. Renew Sustain Energy Rev 2016;53:1389-410. doi:10.1016/j.rser.2015.09.027.

[18] Freni A, Maggio G, Sapienza A, Frazzica A, Restuccia G, Vasta S. Comparative analysis of promising adsorbent/adsorbate pairs for adsorptive heat pumping, air conditioning and refrigeration. Appl Therm Eng 2016;104:8595. doi:10.1016/j.applthermaleng.2016.05.036.

[19] Frazzica A, Freni A. Adsorbent working pairs for solar thermal energy storage in buildings. Renew Energy 2017;110:87-94. doi:10.1016/j.renene.2016.09.047.

[20] Frazzica A, Füldner G, Sapienza A, Freni A, Schnabel L. Experimental and theoretical analysis of the kinetic performance of an adsorbent coating composition for use in adsorption chillers and heat pumps. Appl Therm Eng 2014;73:1020-9. doi:10.1016/j.applthermaleng.2014.09.004.

[21] Jeremias F, Fröhlich D, Janiak C, Henninger SK, Felix Jeremias, Dominik Fröhlich, et al. Water and methanol adsorption on MOFs for cycling heat transformation processes. New J Chem 2014;38:1846. doi:10.1039/c3nj01556d.

[22] Boman DB, Hoysall DC, Pahinkar DG, Ponkala MJ, Garimella S. Screening of working pairs for adsorption heat pumps based on thermodynamic and transport characteristics. Appl Therm Eng 2017;123:422-34. doi:10.1016/j.applthermaleng.2017.04.153.

[23] Kakiuchi H, Shimooka S, Iwade M, Oshima K, Yamazaki M, Terada S, et al. Novel water vapor adsorbent FAM-Z01 and its applicability to an adsorption heat pump. Kagaku Kogaku Ronbunshu 2005;31:361-4. doi:10.1252/kakoronbunshu.31.361.

[24] Kakiuchi H, Shimooka S, Iwade M, Oshima K, Yamazaki M, Terada S, et al. Water Vapor Adsorbent FAM-Z02 and Its Applicability to Adsorption Heat Pump. KAGAKU KOGAKU RONBUNSHU 2005;31:273-7. doi:10.1252/kakoronbunshu.31.273.

[25] Tamainot-Telto Z, Metcalf SJ, Critoph RE, Zhong Y, Thorpe R. Carbon-ammonia pairs for adsorption refrigeration applications: ice making, air conditioning and heat pumping. Int J Refrig 2009;32:1212-29. doi:10.1016/j.ijrefrig.2009.01.008.

[26] Gordeeva LG, Aristov YI. Composites "salt inside porous matrix" for adsorption heat transformation: A current state-of-the-art and new trends. Int J Low-Carbon Technol 2012;7:288-302. doi:10.1093/ijlct/cts050.

[27] Aristov YI, Restuccia G, Cacciola G, Parmon VN. A family of new working materials for solid sorption air conditioning systems. Appl Therm Eng 2002;22:191-204. doi:10.1016/S1359-4311(01)00072-2.

[28] Simonova IA, Freni A, Restuccia G, Aristov YI. Water sorption on composite "silica modified by calcium nitrate." Microporous Mesoporous Mater 2009;122:223-8. doi:10.1016/j.micromeso.2009.02.034.

[29] Gordeeva LG, Freni A, Krieger TA, Restuccia G, Aristov YI. Composites "lithium halides in silica gel pores": Methanol sorption equilibrium. Microporous Mesoporous Mater doi:10.1016/j.micromeso.2007.09.040.

[30] Aristov YI, Gordeeva LG, Pankratiev YD, Plyasova LM, Bikova I V., Freni A, et 
al. Sorption equilibrium of methanol on new composite sorbents "caCl 2/silica gel." Adsorption 2007;13:121-7. doi:10.1007/s10450-007-9012-x.

[31] Gordeeva L, Aristov Y. Novel sorbents of ethanol "salt confined to porous matrix" for adsorptive cooling. Energy 2010;35:2703-8. doi:10.1016/j.energy.2009.04.001.

[32] Henninger SK, Ernst SJ, Gordeeva L, Bendix P, Fröhlich D, Grekova AD, et al. New materials for adsorption heat transformation and storage. Renew Energy 2017;110:59-68. doi:10.1016/j.renene.2016.08.041.

[33] Elsayed E, Al-Dadah R, Mahmoud S, Elsayed A, Anderson PA. Aluminium fumarate and CPO-27(Ni) MOFs: Characterization and thermodynamic analysis for adsorption heat pump applications. Appl Therm Eng 2016;99:802-12. doi:10.1016/j.applthermaleng.2016.01.129.

[34] Ilis GG. Influence of new adsorbents with isotherm Type V on performance of an adsorption heat pump. Energy 2017;119:86-93. doi:10.1016/j.energy.2016.12.053.

[35] Calabrese L, Brancato V, Bonaccorsi L, Frazzica A, Caprì A, Freni A, et al. Development and characterization of silane-zeolite adsorbent coatings for adsorption heat pump applications. Appl Therm Eng 2017;116:364-71. doi:10.1016/j.applthermaleng.2017.01.112.

[36] Calabrese L, Bonaccorsi L, Freni A, Proverbío E. Silicone composite foams for adsorption heat pump applications. Sustain Mater Technol 2017;12:27-34. doi:10.1016/j.susmat.2017.04.002.

[37] Kim C, Cho K, Kim SK, Lee EK, Kim JN, Choi M. Alumina-coated ordered mesoporous silica as an efficient and stable water adsorbent for adsorption heat pump. Microporous Mesoporous Mater 2017;239:310-5. doi:10.1016/j.micromeso.2016.10.014.

[38] Pinheiro JM, Valente AA, Salústio S, Ferreira N, Rocha J, Silva CM. Application of the novel ETS-10/water pair in cyclic adsorption heating processes: Measurement of equilibrium and kinetics properties and simulation studies. Appl Therm Eng 2015;87:412-23. doi:10.1016/j.applthermaleng.2015.05.011.

[39] Zhu LQ, Tso CY, Chan KC, Wu CL, Chao CYH, Chen J, et al. Experimental investigation on composite adsorbent-Water pair for a solar-powered adsorption cooling system. Appl Therm Eng 2018;131:649-59.

[40] Poyelle F, Guilleminot J, Meunier F. Experimental Tests and Predictive Model of an Adsorptive Air Conditioning Unit. Ind Eng Chem 1999;38:298-309. doi:10.1021/ie9802008.

[41] Zhang LZ, Wang L. Effects of coupled heat and mass transfers in adsorbent on the performance of a waste heat adsorption cooling unit. Appl Therm Eng 1999;19:195-215. doi:10.1016/S1359-4311(98)00023-4.

[42] Restuccia G, Freni A, Maggio G. A zeolite-coated bed for air conditioning adsorption systems: Parametric study of heat and mass transfer by dynamic simulation. Appl. Therm. Eng., vol. 22, 2002, p. 619-30. doi:10.1016/S13594311(01)00114-4.

[43] Freni A, Frazzica A, Dawoud B, Chmielewski S, Calabrese L, Bonaccorsi L. Adsorbent coatings for heat pumping applications: Verification of hydrothermal and mechanical stabilities. Appl. Therm. Eng., vol. 50, 2013, p. 1658-63. doi:10.1016/j.applthermaleng.2011.07.010.

[44] Freni A, Bonaccorsi L, Calabrese L, Caprì A, Frazzica A, Sapienza A. SAPO-34 
coated adsorbent heat exchanger for adsorption chillers. Appl Therm Eng 2015;82:1-7. doi:10.1016/j.applthermaleng.2015.02.052.

[45] Radu AI, Defraeye T, Ruch P, Carmeliet J, Derome D. Insights from modeling dynamics of water sorption in spherical particles for adsorption heat pumps. Int J Heat Mass Transf 2017;105:326-37. doi:10.1016/j.ijheatmasstransfer.2016.09.079.

[46] Girnik IS, Grekova AD, Gordeeva LG, Aristov YI. Dynamic optimization of adsorptive chillers: Compact layer vs. bed of loose grains. Appl Therm Eng 2017;125:823-9. doi:10.1016/j.applthermaleng.2017.06.141.

[47] Ramji HR, Leo SL, Abdullah MO. Parametric study and simulation of a heatdriven adsorber for air conditioning system employing activated carbonmethanol working pair. Appl Energy 2014;113:324-33. doi:10.1016/j.apenergy.2013.07.017.

[48] Núñez T, Mittelbach W, Henning HM. Development of an adsorption chiller and heat pump for domestic heating and air-conditioning applications. Appl Therm Eng 2007;27:2205-12. doi:10.1016/j.applthermaleng.2005.07.024.

[49] Kowsari MM, Niazmand H, Tokarev MM. Bed configuration effects on the finned flat-tube adsorption heat exchanger performance: Numerical modeling and experimental validation. Appl Energy 2017. doi:10.1016/j.apenergy.2017.11.019.

[50] Rivero-Pacho AM, Critoph RE, Metcalf SJ. Modelling and development of a generator for a domestic gas-fired carbon-ammonia adsorption heat pump. Renew Energy 2017;110:180-5. doi:10.1016/j.renene.2017.03.089.

[51] Wittstadt U, Füldner G, Laurenz E, Warlo A, Große A, Herrmann R, et al. A novel adsorption module with fiber heat exchangers: Performance analysis based on driving temperature differences. Renew Energy 2017;110:154-61. doi:10.1016/j.renene.2016.08.061.

[52] Graf S, Lanzerath F, Sapienza A, Frazzica A, Freni A, Bardow A. Prediction of SCP and COP for adsorption heat pumps and chillers by combining the largetemperature-jump method and dynamic modeling. Appl Therm Eng 2016;98:900-9.

[53] San JY, Tsai FK. Testing of a lab-scale four-bed adsorption heat pump. Appl Therm Eng 2014;70:274-81. doi:10.1016/j.applthermaleng.2014.05.014.

[54] Frazzica A, Palomba V, Dawoud B, Gullì G, Brancato V, Sapienza A, et al. Design, realization and testing of an adsorption refrigerator based on activated carbon/ethanol working pair. Appl Energy 2016;174:15-24.

[55] Sapienza A, Gullì G, Calabrese L, Palomba V, Frazzica A, Brancato V, et al. An innovative adsorptive chiller prototype based on 3 hybrid coated/granular adsorbers. Appl Energy 2016;179:929-38. doi:10.1016/j.apenergy.2016.07.056.

[56] Palomba V, Vasta S, Freni A. Experimental testing of AQSOA FAM Z02/water adsorption system for heat and cold storage. Appl Therm Eng 2017;124:96774.

[57] Fernandes MS, Brites GJVN, Costa JJ, Gaspar AR, Costa VAF. Modeling and parametric analysis of an adsorber unit for thermal energy storage. Energy 2016;102:83-94. doi:10.1016/j.energy.2016.02.014.

[58] Fernandes MS, Brites GJVN, Costa JJ, Gaspar AR, Costa VAF. A thermal energy storage system provided with an adsorption module - Dynamic modeling and viability study. Energy Convers Manag 2016;126:548-60. 
doi:10.1016/j.enconman.2016.08.032.

[59] Sawin JL, Seyboth K, Sverrisson F. Renewables 2017: Global status report. 2017.

[60] Li XH, Hou XH, Zhang X, Yuan ZX. A review on development of adsorption cooling - Novel beds and advanced cycles. Energy Convers Manag 2015;94:221-32. doi:10.1016/j.enconman.2015.01.076. 


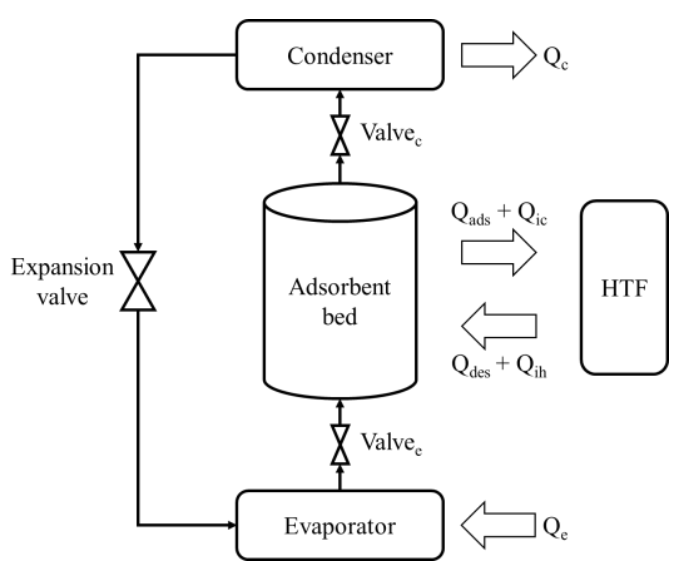




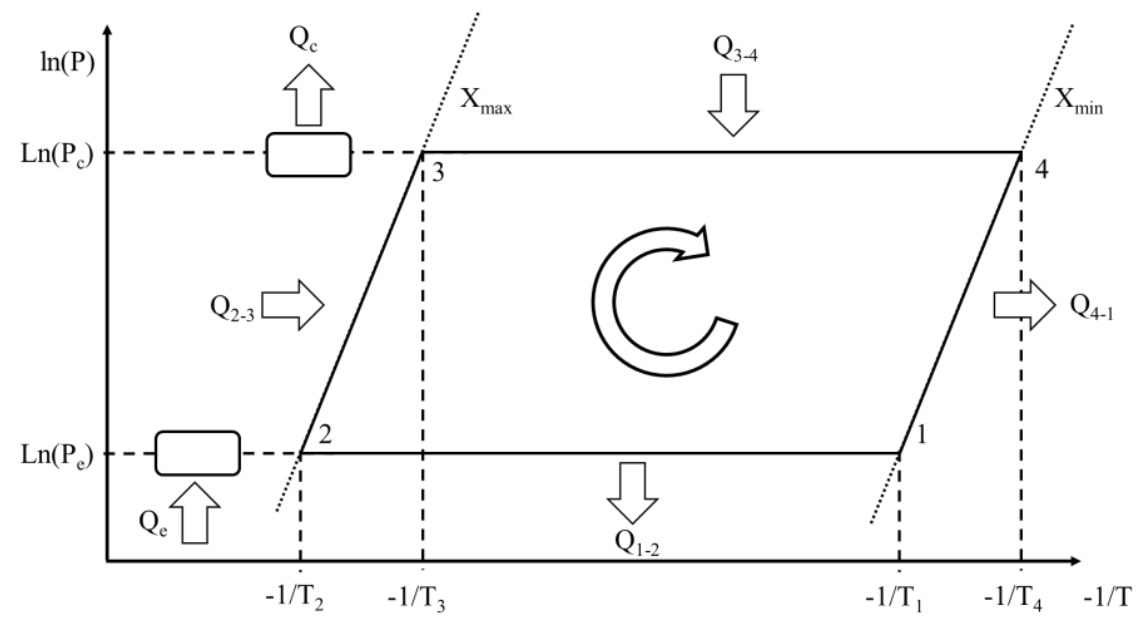




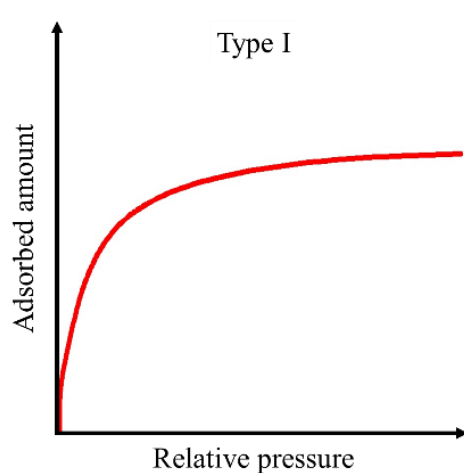

Relative pressure

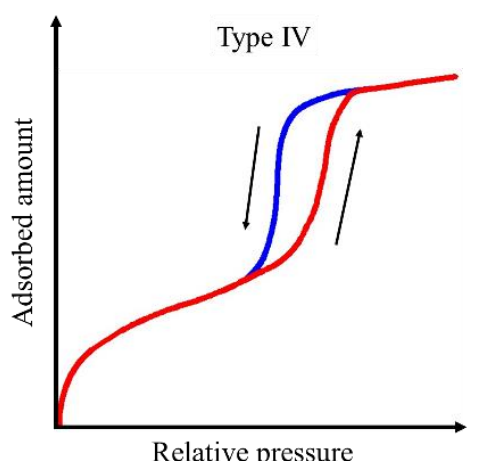

Relative pressure

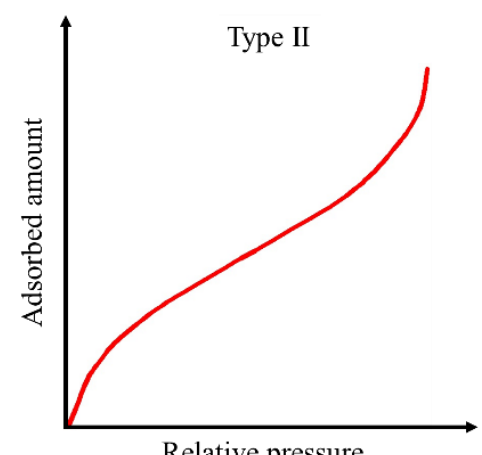

Relative pressure

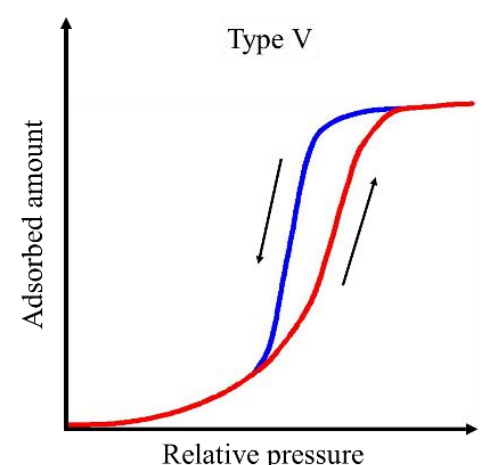

Relative pressure

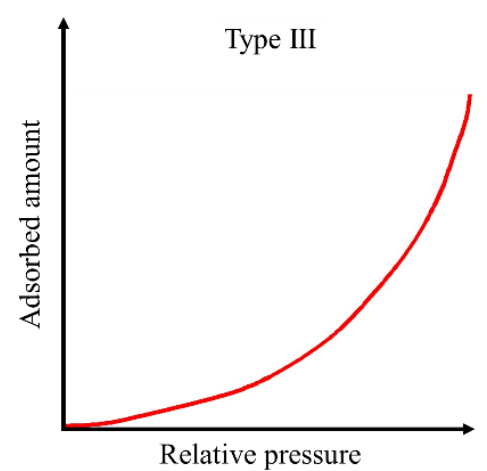

Relative pressure

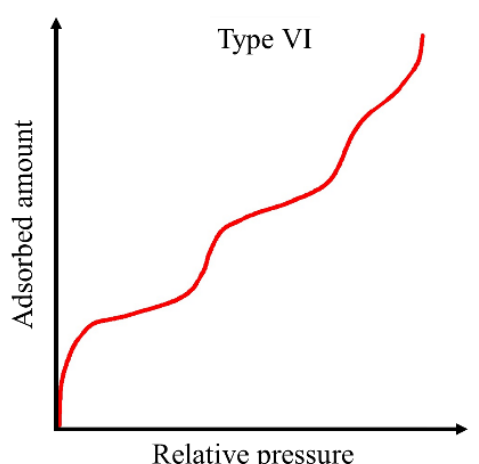

Relative pressure 

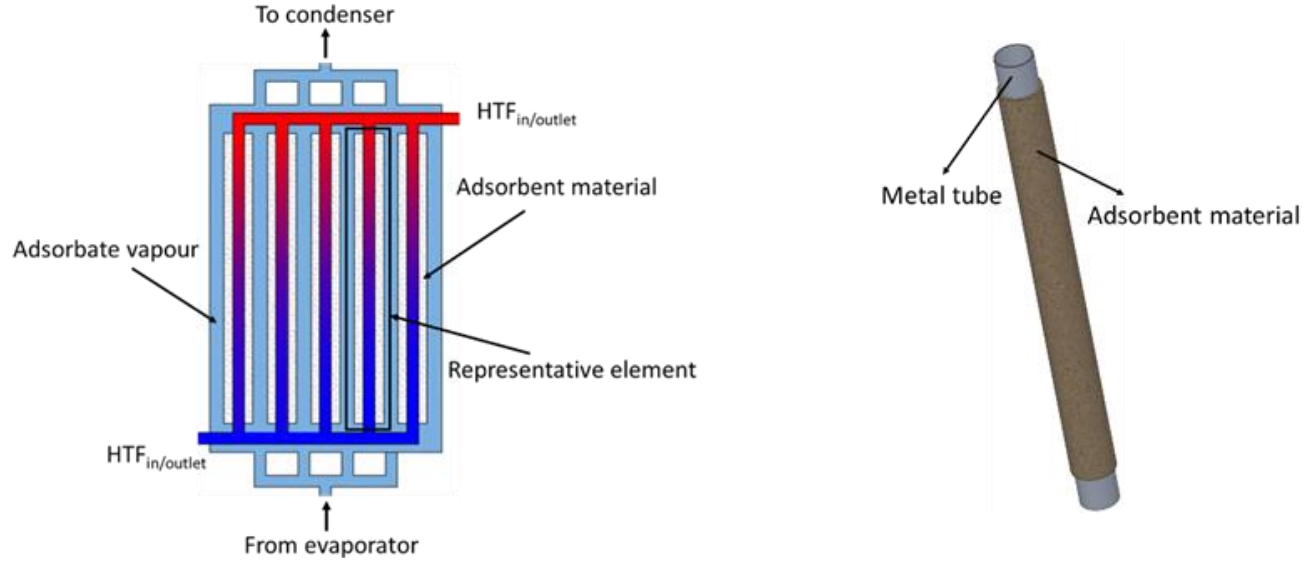


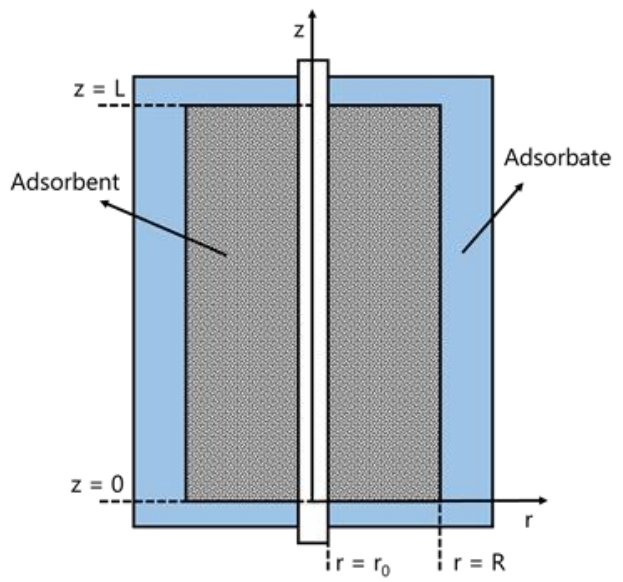



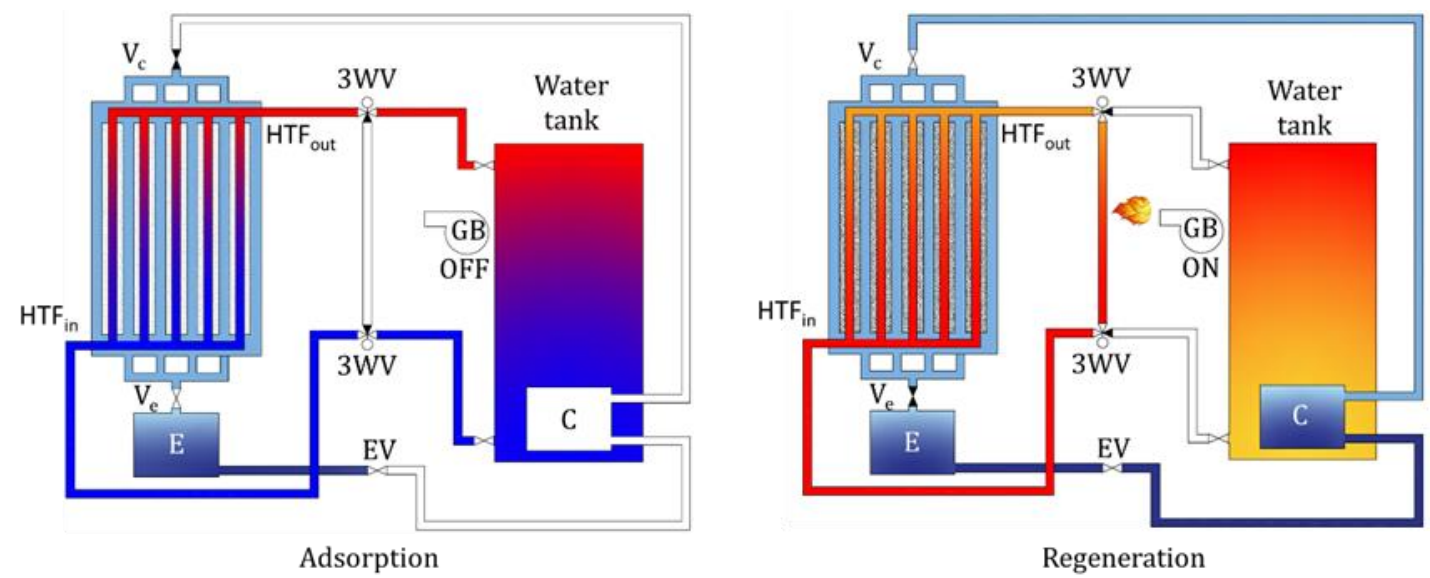